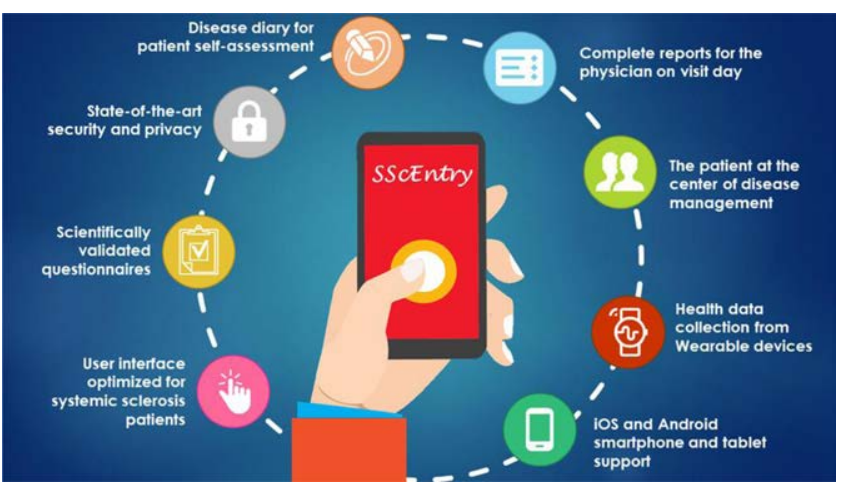

Figure 2. SScEntry features.

Conclusion: Novel Narrative-based Medicine approaches are getting increasing attention to enhance the mutual understanding between patient and physician, reinforcing the therapeutic adherence at the core of healthcare. This is particularly important with chronic and disabling diseases like SSc. Involving patients in disease management with SScEntry will increase their compliance and confidence, with benefits on psychological well-being. Expected benefits for rheumatologists include better evaluation of target therapy and outcomes, as no data on disease activity is lost during the patient clinical history.

References:

[1] J. Varga et al. (2017) Pathogenesis of systemic sclerosis: recent insights of molecular and cellular mechanisms and therapeutic opportunities. J Scleroderma Relat Disord 2:137-52.

[2] L. Mouthon et al. (2017) Patients' views and needs about systemic sclerosis and its management: a qualitative interview study. BMC Musculoskelet Disord 18(1):230.

[3] M. Bradway et al. (2015) Mobile Health: empowering patients and driving change. Trends in Endocrinology \& Metabolism, 26(3):114-117.

Disclosure of Interests: Emanuela Praino: None declared, Floriano Scioscia: None declared, Crescenzio Scioscia: None declared, Giuseppe Loseto: None declared, Filippo Gramegna: None declared, Saverio leva: None declared, Agnese Pinto: None declared, Michele Ruta: None declared, Eugenio Di Sciascio: None declared, Giovanni Lapadula: None declared, Florenzo lannone Consultant of: Speaker and consulting fees from AbbVie, Eli Lilly, Novartis, Pfizer, Roche, Sanofi, UCB, MSD, Speakers bureau: Speaker and consulting fees from AbbVie, Eli Lilly, Novartis, Pfizer, Roche, Sanofi, UCB, MSD DOI: 10.1136/annrheumdis-2020-eular.6067

\section{THU0629-HPR COULD THE ASAS HEALTH INDEX BE A USEFUL INSTRUMENT IN ASSESSING PATIENTS WITH PSORIATIC ARTHRITIS?}

I. Morante Bolado ${ }^{1}$, E. Aurrecoechea', I. Villa-Blanco ${ }^{1}$, M. Santos Gómez ${ }^{1}$, L. Riancho-Zarrabeitia ${ }^{1}$, J. L. Martín-Varillas ${ }^{1}$, R. Queiró Silva ${ }^{2}{ }^{1}$ Sierrallana Hospital, Torrelavega, Spain; ${ }^{2}$ Central University Hospital of Asturias, Oviedo, Spain

Background: At present, there is a growing tendency to use instruments that capture, in the best possible way, the impact that the spondyloarthritides (SpA) generate on patients' lives. For that purpose, tools such as the Psoriatic Arthritis Impact of Disease (PsAID), for psoriatic arthritis (PsA), and the Assessment of SpondyloArthritis international Society-Health Index (ASAS-HI), for SpA, have been recently developed and validated. However, the performance of the ASAS-HI to assess the impact of disease in psoriatic arthritis is barely known.

Objectives: To determine the possible application of ASAS HI to assess PsA by comparing its results to other PsA measurement tools.

Methods: In this observational, cross-sectional study, 89 consecutive patients with PsA (CASPAR criteria) were included. The convergent validity of ASAS-HI (Spearman's rho) and its discriminative validity (ROC curves) was analyzed against other PsA measures (DAPSA and PsAID).

Results: ASAS HI showed a high convergent validity both against DAPSA (rho $0.78, p<0.0001$ ) and PsAID (rho 0.80, $p<0.0001$ ). PsAID and DAPSA also showed high convergent validity (rho $0.79, p<0.0001$ ). ASAS HI showed a high discriminative capacity for both DAPSA remission [optimal criterion $\leq 2$, area under the ROC curve 0.92 (95\%Cl: $0.85-0.97$ ), sensitivity $73 \%$, specificity $94 \%$, $\mathrm{p}<0.0001$ ] (fig 1) and DAPSA low activity state [optimal criterion $\leq 10.6$, area under the ROC curve 0.87 (95\%Cl: $5-10.6$ ), sensitivity $93 \%$, specificity $61 \%, p$ $<0.0001]$. PsAID also demonstrated a high discriminative capacity for DAPSA remission [optimal criterion $\leq 0.8$, area under the ROC curve $0.94(95 \% \mathrm{Cl}$ : 0.55 0.95 ), sensitivity $76 \%$, specificity $100 \%, p<0.0001$ ] and DAPSA low activity [optimal criteria $\leq 4.9$, area under the ROC curve 0.83 (95\% Cl: 3.4-5.2), sensitivity $92 \%$, specificity $61 \%, \mathrm{p}<0.0001]$.

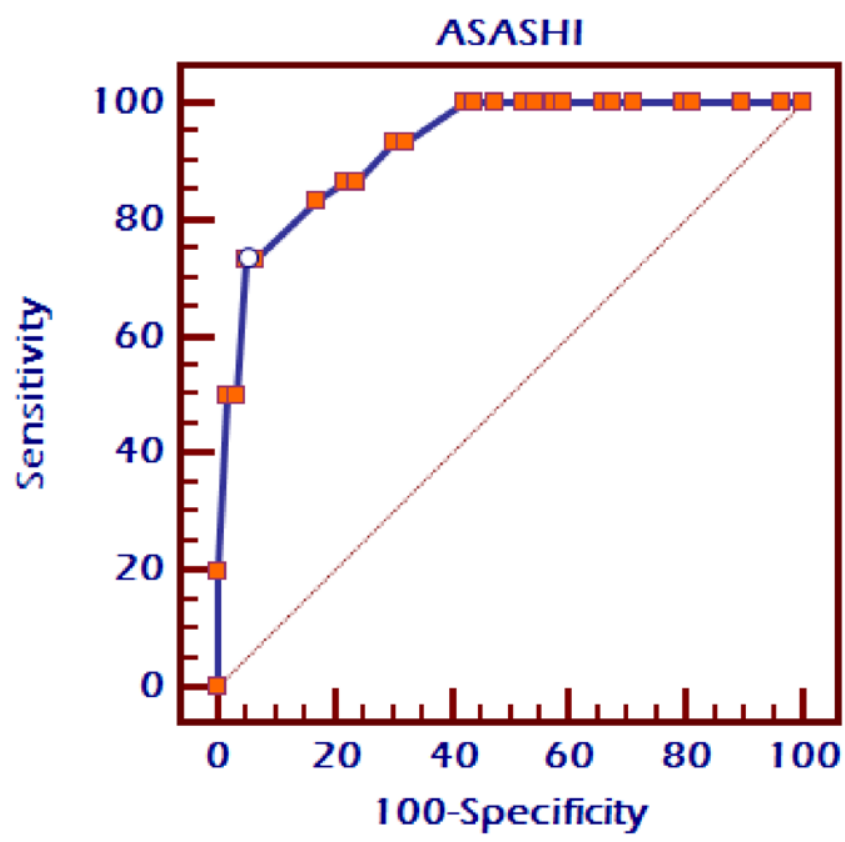

Figure 1. ROC curve analysis between DAPSA remission and ASAS H

Conclusion: ASAS HI could be used as an appropriate tool in the assessment of patients with PsA.

Disclosure of Interests: Isla Morante Bolado: None declared, Elena Aurrecoechea: None declared, Ignacio Villa-Blanco Consultant of: UCB, Speakers bureau: Novartis, MSD, Lilly, Montserrat Santos Gómez: None declared, Leyre Riancho-Zarrabeitia Grant/research support from: Yes, Speakers bureau: Yes, José Luis Martín-Varillas Grant/research support from: AbbVie, Pfizer, Janssen and Celgene, Speakers bureau: Pfizer and Lilly, Rubén Queiró Silva: None declared

DOI: 10.1136/annrheumdis-2020-eular.6296

\section{THU0630-HPR ADVERSE EVENTS, ADVERSE REACTIONS AND MEDICATION-RELATED PROBLEMS ASSOCIATED WITH THE USE OF MEDICINES IN REUMATOID ARTHRITIS}

W. Rivero ${ }^{1}$, P. Rodriguez ${ }^{1}$, M. Cabrera ${ }^{2}$, P. Santos-Moreno ${ }^{3}{ }^{1}$ Biomab Center for Rheumatoid Arthritis, Pharmaceutical Chemist, Bogota, Colombia; ${ }^{2}$ Biomab - Center for Rheumatoid Arthritis, Data Administration, Bogota, Colombia; ${ }^{3}$ Biomab - Center for Rheumatoid Arthritis, Rheumatology, Bogota, Colombia

Background: According to the Third Consensus of Granada of the WHO an adverse event $(\mathrm{AE})$ is an unfortunate situation/event that occurs during the pharmacological treatment of a disease and that may not necessarily be related to the use of one or more medications. An adverse reaction (AR) is an unfortunate situation/event that is directly related to the use of a medicine. A medication-related problem (MRP) is an unexpected result in the treatment with a certain medication, resulting in the appearance of adverse events/reactions.

Objectives: Determine and analyze the incidence of adverse events, adverse reactions and medication-related problems in patients treated for rheumatoid arthritis.

Methods: Of a large cohort of approximately 6,000 patients with rheumatoid arthritis (RA) in a specialized center, between 2018 and 2019 pharmaceutical chemist intervention was performed on those patients who reported AEs, ARs and MRPs during their treatment. These reports were made by the treating doctors, the pharmaceutical chemist and directly by the patients to the treating institution. Interaction between medications, adherence to them, patient lifestyles during pharmacotherapy, sociodemographic variables and support relative networks were monitored and investigated. The severity of the events and reactions was evaluated using the Dader method of therapeutic drug monitoring, Morisky Green test to measure adherence and the variables of the Naranjo algorithm in order to characterize them as AEs, ARs or MRPs and determine level of damage 


\begin{tabular}{|c|c|c|c|c|c|c|c|}
\hline \multicolumn{4}{|l|}{ GENDER } & \multicolumn{3}{|c|}{ TYPE OF EVENT/REACTION } & \multirow{2}{*}{$\begin{array}{c}\text { Men } \\
\text { Women }\end{array}$} \\
\hline 44 & $15 \%$ & convDMARDs & 178 & BIOLOGICS & 118 & & \\
\hline \multirow[t]{2}{*}{252} & $85 \%$ & Cardiovascular & 5 & Cardiovascular & 23 & $\mathrm{p}<0.05$ & AGE \\
\hline & & Dermatological & 37 & Dermatological & 55 & $\mathrm{p}<0.05$ & Betw 20 and 40 yo \\
\hline 74 & $25 \%$ & Digestive & 84 & Digestive & 9 & $\mathrm{p}<0.05$ & Betw 45 and 50 yo \\
\hline 68 & $23 \%$ & Inflamatory & 23 & Inflamatory & 16 & & Betw 51 and 70 yo \\
\hline 33 & $11 \%$ & Non-adherence & 15 & Non-adherence & 8 & & Betw 70 and 79 yo \\
\hline 107 & $36 \%$ & Neurological & 8 & Neurological & 0 & $\mathrm{p}<0.05$ & Betw 80 and 99 yo \\
\hline \multirow[t]{2}{*}{14} & $5 \%$ & Respiratory & 6 & Respiratory & 7 & & TYPE OF THERAPY \\
\hline & & convDMARDs & 181 & $61 \%$ & Biologics & 115 & $39 \%$ \\
\hline CAUSALITY & & & Probable & 236 & $79 \%$ & Possible & 46 \\
\hline $16 \%$ & Unlikely & 14 & $5 \%$ & & & & \\
\hline
\end{tabular}

to the patient. The cases were analyzed in the pharmacovigilance committee of institution and their causality is defined giving solution to the cases and their follow-up according to relevance.

Results: The analysis yielded a cohort of RA 296 patients (44 men-15\%, 252 women-85\%) who reported AEs, Ars and MRPs. 181 patients $(61 \%)$ in management with conventional DMARDS and 115 patients (39\%) in biological therapy were identified. The highest incidence occurs in ages between 70 and 79 years ( $36 \%$ of cases); more commonly in women ( $85 \%$ of cases); more commonly using convDMARDs ( $61 \%$ of cases), all this being statistically significant $(p<0.05)$. The classification resulted in 66 (22\%) AEs, $117(40 \%)$ ARs and 35 $(12 \%)$ MRPs. The reported causality was probable in 236 cases $(79 \%)$, possible 46 cases (16\%), unlikely: 14 cases (5\%) according to the classification of the Naranjo algorithm.

\section{Classification of AEs, ARs and MRPs}

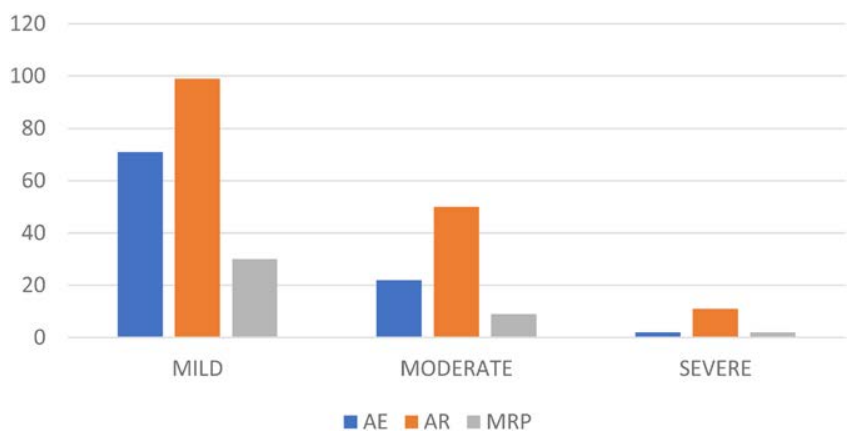

Conclusion: The range of population where AEs, ARs and MRPs most occur are in people over 70 years old; are more common in women and in those who are in conventional DMARDs therapy. The most common AEs, Ars and MRPs with conventional therapy are digestive disorders and in case of biological therapy are dermatological reactions with a mainly probable causality. More studies are needed to clarify these results.

References:

[1] Third Consensus of Granada on Drug Related Problems (DRP) and Negative

Outcomes associated with Medication (NOM). Ars Pharm 2007; 48 (1): 5-17

Acknowledgments: This project was carried out by the scientific direction and the pharmacy of Biomab - Center for Rheumatoid Arthritis

Disclosure of Interests: Wilberto Rivero: None declared, Pedro Rodriguez: None declared, Michael Cabrera: None declared, Pedro Santos-Moreno Grant/ research support from: I have received research grants from Abbvie, BiopasUCB, Janssen, Novartis, Pfizer., Speakers bureau: I have been a speaker for Abbvie, Biopas-UCB, Janssen, Lilly, Novartis, Pfizer, Roche, Sanofi. DOI: 10.1136/annrheumdis-2020-eular.5946

\section{THU0631-HPR EARLY ARTHRITIS GLOBAL ASSESSMENT: WHAT DIFFERENCES EXIST BETWEEN PATIENTS AND PHYSICIANS?}

C. Valero ${ }^{1}$, S. C. Rodriguez-García ${ }^{2}$, N. García Castañeda ${ }^{3}$, J. P. Baldivieso ${ }^{3}$ E. Patiño ${ }^{3}$, A. Ortiz $^{3}$, I. González-Álvaro on behalf of Hospital de la Princesa. ${ }^{1}$ Madrid, Hospital de la Princesa, Madrid, Spain; ${ }^{2}$ Hospital de la Princesa, Madrid, Spain; ${ }^{3}$ Hospital de La Princesa, Madrid, Spain

Background: In recent years there is a growing interest in the assessment of rheumatoid arthritis through patient reported outcomes measures (PROMs). Nonetheless, discrepancies in the disease global disease assessment reported by patients (PtGA) or physicians (PhGA) have been previously described.
Objectives: Our aim was to evaluate differences between PtGA and PhGA and their predictors in an early arthritis cohort

Methods: Cross-sectional study analyzing data from the baseline visit of patients included in the PEARL study (Princess Early Arthritis Register Longitudinal Study) in which demographic, laboratory and clinical characteristics including PtGA and PhGA (0-100 mm) are systematically collected.

The main variable was the difference between PtGA and PhGA $(\Delta G A)$. The descriptive analysis was performed using the Kruskal-Wallis, Mann-Whitney or Pearson correlation tests as appropriate.

A multivariate linear regression model was developed with $\triangle \mathrm{GA}$ as a dependent variable. All those predictors available at the baseline visit reaching a $p$ $<0.15$ in the univariate analysis were included in the initial model. The final one was obtained through the progressive elimination of those variables not showing an improvement in the model as assessed by the adjusted $\mathrm{R}^{2}$ parameter considering those that had a $p>0.15$. To categorize the dependent variable differences between PtGA and PhGA were considered relevant when greater than 5 points.

Results: 530 patients were included, 422 (79.6\%) were women with a mean age of $55.3+/-16$ years, $21.2 \%$ current smokers, $54 \%$ and $50.4 \%$ rheumatoid factor and anti-CCP positive respectively. A $43.3 \%$ had moderate activity and $33.6 \%$ high, measured by DAS28-VSG.

The median of $\triangle \mathrm{GA}$ was 4 , (interquartile range; -10 to 18 ; see figure 1 ). In $22 \%$ of the cases patients and physicians scored the same, in $46.5 \%$ the patients' scores were higher and physicians' were so in $31.5 \%$ of the cases.

The variables that explained $\triangle \mathrm{GA}$ after adjusting the multivariate model were pain $[\beta=0.36(95 \% \mathrm{Cl} 0.28$ to 0.44$)]$, number of swollen joints $[\beta=-3.19(95 \% \mathrm{Cl}$ -3.7 to -2.7$)]$ and $E S R[\beta=-0.11(95 \% \mathrm{Cl}-0.2$ to -0.03$)]$. Pain had a greater influence on patients' opinion while the number of swollen joints and ESR were more relevant for physicians. Other variables such as race, marital status, profession, sex, smoking, seropositivity or disease activity were not relevant in the prediction of $\triangle \mathrm{GA}$.

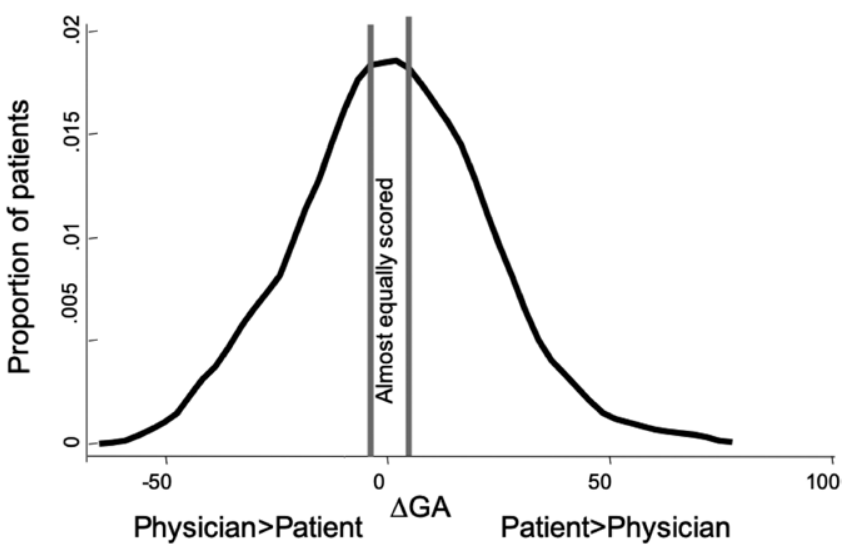

Conclusion: In our cohort, disagreements between PtGA and PhGA were observed. Patients scored higher based on painful perception and physicians did so relying on objective evidence of inflammation.

Disclosure of Interests: Cristina Valero: None declared, Sebastian C Rodriguez-García Speakers bureau: Novartis Farmaceutica, S.A., Merck Sharp \& Dohme España, S.A., Sanofi Aventis, UCB Pharma, Noelia García Castañeda: None declared, Juan Pablo Baldivieso: None declared, Esther Patiño: None declared, Ana Ortiz: None declared, Isidoro González-Álvaro Grant/research support from: Roche Laboratories, Consultant of: Lilly, Sanofi, Paid instructor for: Lilly, Speakers bureau: Abbvie, MSD, Roche, Lilly

DOI: 10.1136/annrheumdis-2020-eular.3380 